\title{
How players across gender and age experience Pokémon Go?
}

\author{
Aqdas Malik $^{1,2,3} \cdot$ Kari Hiekkanen ${ }^{1} \cdot$ Zaheer Hussain $^{4} \cdot$ Juho Hamari $^{2} \cdot$ Aditya Johri $^{3}$
}

Published online: 16 October 2019

(c) The Author(s) 2019

\begin{abstract}
The purpose of this study is to provide insights into player experiences and motivations in Pokémon Go, a relatively new phenomenon of location-based augmented reality games. With the increasing usage and adoption of various forms of digital games worldwide, investigating the motivations for playing games has become crucial not only for researchers but for game developers, designers, and policy makers. Using an online survey $(N=1190)$, the study explores the motivational, usage, and privacy concerns variations among age and gender groups of Pokémon Go players. Most of the players, who are likely to be casual gamers, are persuaded toward the game due to nostalgic association and word of mouth. Females play Pokémon Go to fulfill physical exploration and enjoyment gratifications. On the other hand, males seek to accomplish social interactivity, achievement, coolness, and nostalgia gratifications. Compared to females, males are more concerned about the privacy aspects associated with the game. With regard to age, younger players display strong connotation with most of the studied gratifications and the intensity drops significantly with an increase in age. With the increasing use of online and mobile games worldwide among all cohorts of society, the study sets the way for a deeper analysis of motivation factors with respect to age and gender. Understanding motivations for play can provide researchers with the analytic tools to gain insight into the preferences for and effects of game play for different kinds of users.
\end{abstract}

Keywords Pokémon Go · Augmented reality games (ARGs) · Location-based games (LBGs) · Online games · Freemium · Free-to-play $\cdot$ Virtual reality $(V R) \cdot$ Uses and gratifications $(U \& G)$

Aqdas Malik

aqdas.a.malik@aalto.fi

Kari Hiekkanen

kari.hiekkanen@aalto.fi

Zaheer Hussain

zaheer.hussain@ntu.ac.uk

Juho Hamari

juho.hamari@tuni.fi

Aditya Johri

johri@gmu.edu

1 Department of Computer Science, Aalto University, Espoo, Finland

2 Gamification Group, Faculty of Information Technology and Communication Science, Tampere University, Tampere, Finland

3 Department of Information Sciences and Technology, George Mason University, Fairfax, VA, USA

4 School of Social Sciences, Nottingham Trent University, Nottingham, UK

\section{Introduction}

One of the most notable gaming phenomena during the current decade that attracted the public toward games has been Pokémon Go by Niantic Labs. Pokémon Go is a freemium/ free-to-play mobile-based augmented reality game launched initially in the USA on July 6, 2016, which has now been widely embraced across the globe. Since its launch, the game has captured exceptional attention in the media as well as in the gaming community. Pokémon Go has inspired many people toward physical and outdoor activity that led to its recognition as the best idea for physical exercise by Suomen Latu (The Outdoor Association of Finland). Furthermore, the game has also been characterized as a highly useful channel for uniting young as well as the older generation in outdoor activities. ${ }^{1}$ During the first 6 months of its launch, the game has also set a number of records including fastest game to be at the top of the charts in the App Store and

\footnotetext{
${ }^{1}$ http://yle.fi/uutiset/osasto/news/Pokémon_go_gets_exercise_award _from_outdoor_activities_group/9247553YLE ${ }^{\text {News } 2016 .}$
} 
Google Play. ${ }^{2}$ Pokémon Go has also been the most downloaded game (and application) during the first week on the App Store. ${ }^{3}$ In 2016, Pokémon Go was among the top search terms in Google, further highlighting its global popularity. ${ }^{4}$

Pokémon Go is a predecessor of Ingress that was also published by Niantic Labs (a spin-off company from Google) back in 2012. By employing GPS technology, Ingress-a free-to-play location-based multiplayer game, developed a complex and robust digital narrative by combing augmented reality with geo-media $[13,30]$. Borrowing the science fiction narrative, the players of the game were set as the agents that contend for controlling real-world locations through the game. Although Ingress was not able to attain the same hype and attention as Pokémon Go, it managed to demonstrate the strong and bright potential of location-based augmented reality applications as well as set a path not only for Pokémon Go, but also for future augmented reality applications. Pokémon Go and Ingress are positioned as location-based augmented reality games as they employ mobile tracking technology by supplementing them with highly playful and close-to-reality interactions. In essence, Pokémon Go and other location-based augmented reality games derive the concept from geocaching, also referred as "GPS-enabled treasure hunt" $[4,52]$. Geocaching is a location-based outdoor activity in which an item is concealed at a location anywhere in the world and its longitude and latitude coordinates are published for other geocachers. The geocachers then use a GPS-enabled device to track and find the hidden treasure $[4,52]$. Pokémon Go (and many other locationbased augmented reality games) replicates and augments the core mechanics of geocaching as it revolves around finding Pokémon creatures (instead of hidden treasure) and battling others with the collected Pokémon. Seeing groups of people playing Pokémon Go, exploring new places, and gathering together and socially interacting with other players in certain "PokéStops," which has become commonplace, is analogous to the geocaching context $[4,52]$.

Although Pokémon Go is not the first mobile game combining the virtual with the physical, it represents one of the first real experiences of location-based gaming bundled with social interactivity features to a wider audience $[14,59]$. Pokémon Go represents a new breed of mobile games that moved gaming from indoors to outdoors, requiring people to walk, jog, or cycle to catch a new Pokémon and exercise to hatch Pokémon eggs among many other

\footnotetext{
2 http://venturebeat.com/2016/07/11/Pokémon-go-outpaces-clash -royale-as-the-fastest-game-ever-to-no-1-on-the-mobile-revenue-chart s/.

${ }^{3}$ https://techcrunch.com/2016/07/22/apple-says-Pokémon-go-is-themost-downloaded-app-in-its-first-week-ever/.

${ }^{4}$ https://www.google.com/2016.
}

activities. The phenomenon associated with outdoor mobile activism through a game (e.g., Ingress and Pokémon Go) that improves one's health has already been witnessed in geocaching applications and has been endorsed by various health organizations and watchdogs 5 as well as by the academic community $[2,4,52,59]$.

Location-based augmented reality games (more specifically Pokémon Go) are a novel gaming genre that syndicates multifaceted features within them to attract a wider gamer demographic than is typically the case with digital games. Due to their adoption and engagement across a diverse population, these games provide a number of gratifications and experiences, as well as raise concerns that are a departure from conventional digital games. For instance, features such as physical activation, outdoor exploration, social interactivity, and health benefits that accrue from those activities, as well as privacy and trust issues that arise due to location and collaboration, are hallmarks of this new gaming genre. While there is a plethora of research on various motives associated with games [24, 37, 58, 65], negative gaming outcomes [11, 12, 34], demographic variations [9, 20, 21, 57], and gamers behaviors on specific games [12, 17, 28, 35], the novelty and rapid popularity of location-based augmented reality games (particularly Pokémon Go) across the highly diverse global audience provides an opportunity to revisit many of the core issues and findings of gaming research [1, $10,23,38]$.

Understanding uses and motivations in digital games is highly essential and relevant not only for scholars but also for game developers and designers, as in recent years games have witnessed massive adoption by non-gamers (and casual gamers) and have become an integral vein of entertainment media. Besides informing variations of in-game attitudes and behaviors among various age and gender groups, a number of demographic-based nuances associated with the usage and adoption of technology in general and games in particular can be observed [57]. Prior research highlights that female gamers differ in playing styles, motives, level of participation, genre choices, expertise, and preferences when compared to their male counterparts [25, 43, 67]. Similarly, there are significant differences among usage, adoption, motivations, and expertise of young and old gamers [21, 32, 34].

Recent research indicates that Pokémon Go has been highly efficacious in appealing to a wide range of gamers, from new gamers to hardcore fans, as well as a large number of females and older age groups. For instance, the study carried out with 18-75 year olds Pokémon Go players in USA illustrates that the game supported the wellbeing of the players in terms of friendship formation and

\footnotetext{
5 http://news.heart.org/Pokémon-go-brings-video-games-outside/.
} 
strengthening as well as walking outdoors [8]. Another study by Kogan et al. [40] investigating the physical and psychological gains through Pokémon Go use by those aged 18-over 50 years old (predominantly females) revealed that the participants spend more time with family and pets after they started playing the game. Furthermore, the players began spending more time outdoors for walking and exercising since they started to play the game [40]. On the other hand, research has also portrayed some of the adverse effects associated with the usage of the game. The study investigating a random sample of 4000 tweets indicates the game posing distraction to drivers, passengers as well as pedestrians that lead to hampered public safety [3]. Another study points out the privacy issues associated with Pokémon Go and similar games as they lack adequate protection, especially for children, such as safety reminders when contacting new users, hiding location by default, and clear processes on safeguarding concerns [49].

As Pokémon Go has also been credited for making digital games mainstream via mobile phones, it remains an intriguing research question as to whether the gratifications (and to a certain extent concerns) vary across different player groups. Additionally, one should also consider whether mobile location-based augmented reality games depict behavioral patterns similar to those indicated by gaming studies or if they differ substantially. In the current study, we investigate two key demographics (gender and age) and how they shape and influence various motivational factors in the context of location-based augmented reality gaming. Furthermore, we investigate the differences that emerge across each of the demographic variables. Thus, this study poses the following research questions:

RQ1: How do various gratifications and concern for privacy vary across gender in the context of Pokémon Go? RQ2: How do various gratifications and concern for privacy vary across different age groups in the context of Pokémon Go?

While this study is investigating the relationship between demographic factors (age and gender) and the gratifications people derive from playing Pokémon Go and while any game such as Pokémon Go has a player base representing a certain kind of demographic make-up, the relationships between demographic factors and gratifications are generally thought to be fairly stable across games and game genres. Pokémon Go can be considered a blueprint of contemporary location-based augmented reality games. Therefore, while the results of the study first and foremost address this relationship in Pokémon Go, the results can also be cautiously generalized to the context of location-based augmented reality games and furthermore cautiously to games in general. Therefore, the present study contributes to our knowledge on the intricate relationships between demographic factors and how we experience games.

\section{Theoretical background}

\subsection{Uses and gratifications framework}

The Uses and Gratification (U\&G) is a theory that explores how and why people use technology to fulfill their needs and motives [55]. This framework assumes that people use technology to satisfy their needs and motivations that play an important role in influencing an individual's intention to use certain technology. The U\&G approach assumes that (1) audiences actively participate, (2) audiences previous experience with technology helps them make motivated choices, and that (3) audiences use technology as one way to satisfy everyday needs [55]. The U\&G framework is one of the media-use theories that is commonly used by researchers and offers a broad application for understanding media usage. The $U \& G$ framework has also been characterized as a highly useful and effective media-use paradigm for diagnosing uses and gratifications of a given technology or service as well as its recurring usage [36]. More recently, the U\&G framework has been considered highly suitable by studies in new media research as a tool for explaining media choices of people [23, 41, 46-48, 53].

In relation to understanding motives and experiences, researchers from various domains have opted for the U\&G framework to investigate motives associated with various genres and forms of games including video games in general $[37,58]$, online games [50,68], social games [12, 28], and mobile games [64]. By employing the $U \& G$ framework as a theoretical foundation for examining gaming motivations, a number of existing gratifications for other media have been validated and some new ones being identified. Some of the notable gratifications include enjoyment, fantasy, escapism (hedonic motives), social interaction/connection and social presence (social motives), and self-presentation, self-expression, and achievement (utilitarian motives) $[12,27-29,35$, $58,70]$.

More recently, the framework has also been adapted to explore and understand the gratifications and motives associated with Pokémon Go. More details on the application of the $U \& G$ framework in some of the notable studies on Pokémon Go are presented in Table 1.

\subsection{Demographic variations in digital games}

\subsubsection{Gender differences}

The role of gender and issues related to various aspects of IS adoption, usage, and attitudes has been actively debated 


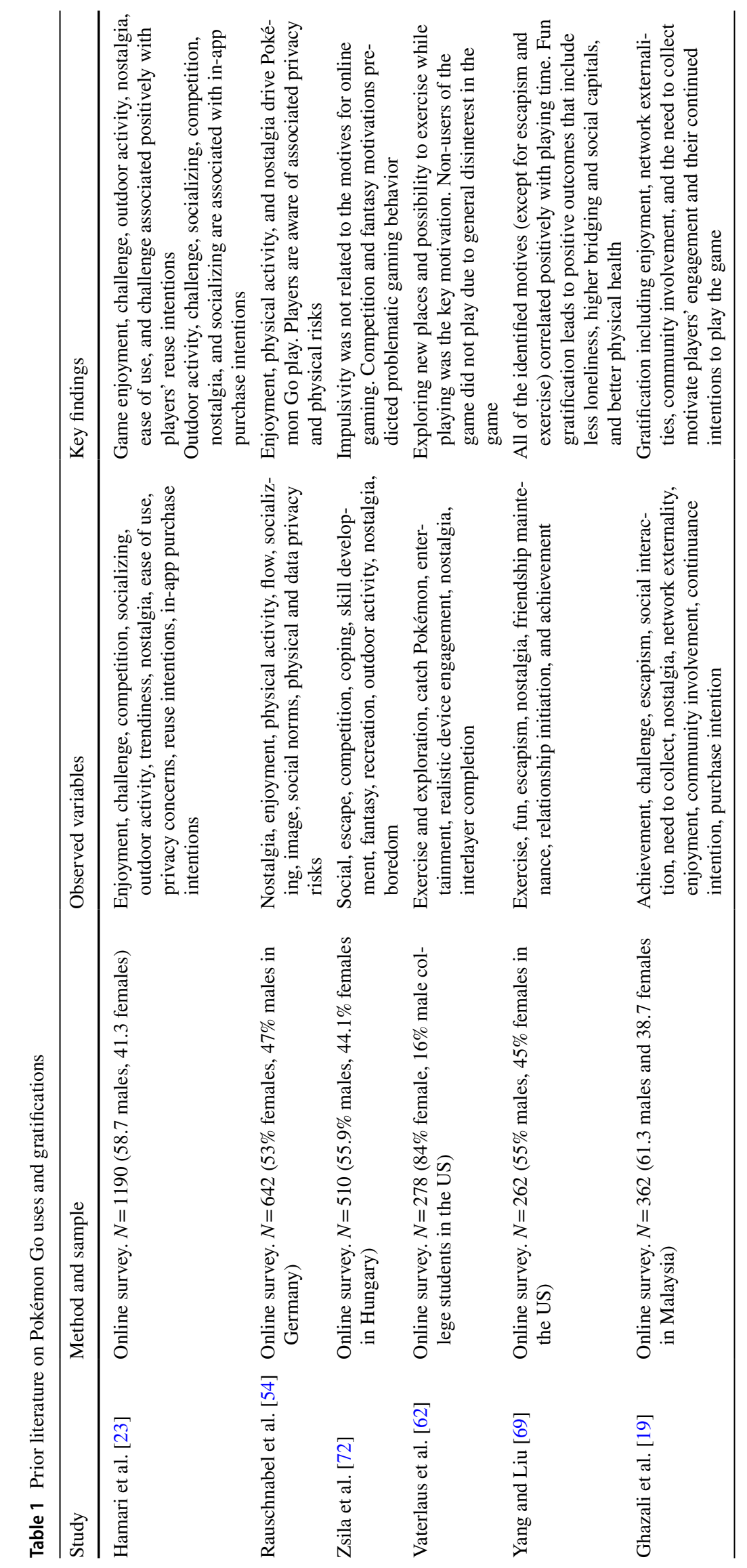


since early 2000, for example, in Computer-mediated communication [16], online shopping [26], information seeking [6], and more recently social media [45-48]. Although digital games are more popular among and played overwhelmingly by males, the rooted notion of digital games being overshadowed by adolescent males and perceived generally as a stereotypical male activity $[43,57]$ has been confronted as games have become mainstream for a wider demographic population [39, 70]. Although female gamers are markedly under-represented in the digital gaming arena, the participation of female gamers has been increasing rapidly and the age span of gamers has also been widening exponentially $[20,25,67,70,71]$. Due to this shift, better understanding of gamer motives, behaviors as well as concerns and how various gamer demographics differ is called for. It is important to understand whether changing gaming devices, such as smartphones, and novel experiences such as gaming outside, have any effect on gender participation.

\subsubsection{Age differences}

In relation to behavioral intentions of users in computermediated environments, age has been one of the predominant factors exerting effects on a number of constructs such as self-efficacy, skill acquisition, trust, willingness to adopt, social/pragmatic dependency, and outcome expectations [44]. Prior research on online information seeking [56], cellular phones [18], tablet devices [44], and social networking sites [46-48], suggests that perceptions, usage, access, adoption, as well as diffusion of various technologies, vary substantially among younger and older age groups.

Much of games research concentrates on studying adolescents and young gamers $[9,11,59]$. Although computer games are played and embraced by all age groups, the research literature indicates that popularity and diffusion of digital games is much higher among adolescents and younger age groups. More recently, studies on old gamers have begun to appear focusing on health and cognitive perspectives $[15,51]$. Despite the ever-increasing popularity of digital games among older age groups, comparisons between adolescents and older age groups, usage, motives, and attitudes have been highly limited. In the gaming literature, gaming has often been characterized as one of the core leisure activities for many adolescents. Consequently, research within academia has given limited attention to older groups of active gamers as it has predominantly focused on adolescents and young gamers. Studying active older gamers and comparing their motivations, activities, attitudes and concerns in contrast with younger gamers have been even more limited.

\section{Methodology}

\subsection{Data and participants}

The data for this study were collected through a webbased survey. By employing the virtual snowball sampling method, the survey targeted participants across the globe who were current players of Pokémon Go or had recently played the game. Virtual snowball sampling is a highly popular technique that has been predominantly employed by a number of recent gaming [12, 28, 64] and social media studies [7, 22, 46-48]. The survey was initially publicized on a number of gaming research mailing lists as well as the Twitter profile of the first author. To minimize the inbuilt biases that are usually observed in traditional snowball sampling, the participants were not invited personally and the survey was marketed in different channels. The main aim of employing this technique was to reach a wider audience/geography and thus actually providing a better base for the generalization of the results [5]. In the brief description of the promotional text, we requested readers to forward/post the survey on relevant forums/ social media channels. During the course of 1 month, the survey link was tweeted by a number of gaming professionals, academics, and research groups. Furthermore, the survey was posted on a number of Pokémon Go Facebook fan pages and groups. Three days prior to the survey closure, we requested that owners/admins of all the traceable forums post a reminder text for their audience.

All the questions in the survey were mandatory. The study procedures were consistent with the ethical principles defined by The Finnish Advisory Board on Research Integrity. Participation in the survey was voluntary, and users could withdraw at any time. During the one-month period, 1315 respondents completed the survey. After the data cleaning process, the final data set consisted of 1190 valid responses. Table 2 lists demographic information of the respondents.

The instrument used in the study was developed from the relevant previous literature including measures for general gaming behavior, uses and gratifications, and concerns for privacy aspects intentions and enjoyment. The gratifications adopted in the current study were specifically chosen due to their significance in the seminal gaming literature and more recently within the context of Pokémon Go (see Table 1). With regard to privacy concerns, we opted to study its role on age and gender as it has often been regarded as a salient factor impacting the use of new media [45-48, 61].

Individual questions were adapted to a Pokémon Go context. As Pokémon Go is one of the first mobile games blending game elements with the actual environment based 
Table 2 Descriptive data of participants $(N=1190)$

\begin{tabular}{|c|c|c|}
\hline Measure & Frequency & Percentage $\%$ \\
\hline \multicolumn{3}{|l|}{ Gender } \\
\hline Male & 698 & 58.7 \\
\hline Female & 492 & 41.3 \\
\hline \multicolumn{3}{|l|}{ Age } \\
\hline$<20$ & 215 & 18.0 \\
\hline $21-25$ & 388 & 32.6 \\
\hline $26-30$ & 302 & 25.4 \\
\hline $31-35$ & 132 & 11.1 \\
\hline $36-40$ & 74 & 6.2 \\
\hline$>40$ & 79 & 6.6 \\
\hline \multicolumn{3}{|l|}{ Education } \\
\hline High school (and below) & 240 & 20.2 \\
\hline Vocational school & 116 & 9.7 \\
\hline College & 421 & 35.4 \\
\hline University & 413 & 34.7 \\
\hline \multicolumn{3}{|l|}{ Occupation } \\
\hline Unemployed & 98 & 8.2 \\
\hline Homemaker (full-time) & 33 & 2.8 \\
\hline Student & 401 & 33.7 \\
\hline Working (full-time) & 550 & 46.2 \\
\hline Working (part-time) & 102 & 8.6 \\
\hline Retired & 6 & 0.5 \\
\hline \multicolumn{3}{|c|}{ Number of games (installed on phone) } \\
\hline$<5$ & 746 & 62.7 \\
\hline $6-10$ & 328 & 27.6 \\
\hline $11-15$ & 61 & 5.1 \\
\hline $16-20$ & 30 & 2.5 \\
\hline$>21$ & 25 & 2.1 \\
\hline \multicolumn{3}{|c|}{ Average time spent on Pokémon Go! daily } \\
\hline$<15 \min$ & 88 & 7.4 \\
\hline $16-30 \mathrm{~min}$ & 149 & 12.5 \\
\hline $31-45 \min$ & 125 & 10.5 \\
\hline $46-60 \mathrm{~min}$ & 157 & 13.2 \\
\hline $1-2 \mathrm{~h}$ & 279 & 23.4 \\
\hline $2-3 \mathrm{~h}$ & 140 & 11.8 \\
\hline $3-4 \mathrm{~h}$ & 101 & 8.5 \\
\hline $4-5 \mathrm{~h}$ & 45 & 3.8 \\
\hline $5-6 \mathrm{~h}$ & 41 & 3.4 \\
\hline$>6 \mathrm{~h}$ & 65 & 5.5 \\
\hline
\end{tabular}

on the player's location, and one where physical exploration of the location is a central game play mechanic, we included a new self-developed construct to measure physical activity and extending virtual-world exploration and immersion concepts to the physical world. All items were measured using seven-point Likert-type scale answers, from "strongly disagree" (1) to "strongly agree" (7). Participants were also asked about the reasons for starting Pokémon Go (Table 3).

\section{Results}

The reliability of the survey instrument was established by testing each construct's reliability and content validity using Cronbach's- $\alpha$. All scores were above the recommended level of 0.70 [60]. Assumptions for normality were tested for all independent variables using histograms. As the first step in our analysis, an independent samples $t$ test was conducted to evaluate how gender affects playing behavior and perceived motivations (Table 4). An alpha level of 0.05 was used for all statistical tests.

Based on the results, there were statistically significant differences between Males and Females in all constructs except Immersion. Male players scored higher for Social Interaction $(t[1188]=3.76, p<0.001)$, Achievement $(t[1175]=4.24, p<0.001)$, Coolness $(t[1148]=4.94$, $p<0.001)$, Privacy concerns $(t[1188]=2.026, p=0.043)$, and Nostalgia $(t[902]=7.715, p<0.001)$, while female players scored higher in Physical Exploration $(t[1137]=-2.31$, $p=0.024)$ and Enjoyment $(t[1148]=5.65, p<0.001)$.

In order to inspect the impact of age on gaming experience while controlling for the time spent playing, a oneway analysis of covariance (ANCOVA) was used. Results of the one-way ANCOVA analysis for different age groups are presented in Table 5. An alpha level of 0.05 was used for all statistical tests.

The results show that age has a statistically significant impact on Social Interaction, Achievement, Immersion, Coolness, Privacy Concerns, and Nostalgia dimensions while controlling for time spent playing. Except for Privacy Concerns, time spent playing is significant covariate for dependent variables. For Privacy Concerns, time spent
Table 3 Stated reasons for starting Pokémon Go-multiple choices $(N=1190)$

\begin{tabular}{lll}
\hline Stated reason & Frequency & Percentage \% \\
\hline Childhood memories of Nintendo games & 737 & 61.9 \\
Previous attachment with Pokémon characters & 602 & 50.6 \\
Recommendation by a friend/family member/colleague & 333 & 28.0 \\
Many people I know are playing it & 315 & 26.5 \\
Discussions in broadcast and social media & 276 & 23.2 \\
Featured/popular app in Play/AppStore & 131 & 11.0 \\
Positive reviews on various websites & 124 & 10.4
\end{tabular}


Table 4 Independent samples $t$ test (Gender)

\begin{tabular}{llllllll}
\hline Construct & Gender & Mean & SD & Cronbach's- $\alpha$ & $t$ test & $p$ & Cohen's $d$ \\
\hline Social interaction & Male & 4.52 & 1.55 & 0.92 & $t(1188)=3.76$ & $<0.001$ & 0.224 \\
& Female & 4.18 & 1.49 & & & & \\
Achievement & Male & 4.86 & 1.33 & 0.87 & $t(1175)=4.24$ & $<0.001$ & 0.242 \\
& Female & 4.57 & 1.04 & & & & \\
Immersion & Male & 4.98 & 1.35 & 0.78 & $t(1119)=1.06$ & 0.295 & 0.062 \\
& Female & 4.90 & 1.22 & & & & \\
Physical exploration & Male & 5.36 & 1.55 & 0.93 & $t(1137)=-2.31$ & 0.024 & 0.130 \\
& Female & 5.55 & 1.35 & & & & \\
Enjoyment & Male & 5.24 & 1.51 & 0.93 & $t(1165)=-5.18$ & $<0.001$ & 0.299 \\
& Female & 5.65 & 1.22 & & & & \\
Coolness & Male & 3.13 & 1.82 & 0.97 & $t(1148)=4.94$ & $<0.001$ & 0.285 \\
\multirow{2}{*}{ Privacy concerns } & Female & 2.65 & 1.54 & & & & \\
\multirow{2}{*}{ Nostalgia** (** scale 0-5) } & Male & 3.93 & 1.82 & 0.89 & $t(1188)=2.026$ & 0.043 & 0.119 \\
& Female & 3.72 & 1.72 & & & & \\
& Female & 3.06 & 1.77 & & $t(902)=7.715$ & $<0.001$ & \\
\hline
\end{tabular}

playing is not significant covariate $(F(1,1183)=0.267$, $p=0.606)$.

To further explore how age impacts these dimensions, Tukey's HSD post-hoc comparisons of age groups were conducted. The Tukey's HSD post-hoc tests indicated that there are significant differences in the adjusted mean scores for Social Interaction, Achievement, and Immersion between age groups 1-2 and 6 (respondents below 25 years and over 40 years). For Privacy Concerns and Nostalgia, Tukey's HSD post-hoc tests revealed significant differences in the adjusted mean scores between age groups 1-2 and 4-6 (respondents below 25 years and over 30 years). For Coolness, Tukey's HSD post-hoc test did not indicate any significant differences between age groups.

The inter-correlation matrix (Table 6) and means plots for these constructs showed that for Achievement, Coolness, Social Interaction, and Nostalgia, the score decreased with age. However, for Privacy Concerns, the score increases slightly with age. For the perceived Enjoyment or Physical Exploration, age seems to have no significant impact. The two-way multivariate analysis of variance (two-way MANOVA) revealed that there is no statistically significant interaction effect between gender and age on the combined dependent variables, $F(35,4932)=1.448, p=0.063$; Wilks' $\Lambda=0.958$.

\section{Discussion}

The present study examined the impact of two key demographic factors, namely gender and age, on a number of gratifications in the context of a mobile location-based augmented reality game-Pokémon Go. Furthermore, the concerns associated with the privacy of personal and gaming data were addressed in the study.

Evidently, nostalgic associations with the game (childhood memories) and the gaming characters (attachment with Pokémon characters) were the key reasons that influenced the participants (reported by more than half of the respondents) to start playing the game (see Table 3). Moreover, social aspects and word of mouth (e.g., recommendations by family/friends and known people playing the game) also persuaded many participants (over one-fourth) to outset their interactions with Pokémon Go. Intriguingly, positive reviews about the game on the web as well as the popularity indices and prominence in various digital distribution platforms (Google Play and App Store) were not considered a significant trigger for playing Pokémon Go. These motivations inducing their Pokémon Go game play may be influenced by the structural characteristics of online games. Previous research [33] has highlighted that specific structural characteristics of online games (such as character development, socialization, and chat features) may induce playing. Therefore, it could be speculated that these characteristics may induce longer playing sessions as users of new online games might enjoy the social aspects.

One of the most interesting findings of this study relates to the gender differences found in game experiences. Previous studies suggest consistently that males enjoy games more than females and highlights female preference for relationship-(social) and coolness-based motivations [20, 25, 63]. Based on our data, females $(M=5.65)$ perceive greater game enjoyment in Pokémon Go than males $(M=5.24)$. Even though enjoyment is rated as significantly more important by females, the mean scores for this gratification are the second highest among males. These results are somewhat 
Table 5 One-way ANCOVA (age)

\begin{tabular}{|c|c|c|c|c|c|}
\hline Age group & $N$ & Mean & SD & ANCOVA & $p$ \\
\hline \multicolumn{6}{|c|}{ Social interaction } \\
\hline$<20$ & 215 & 4.56 & 1.49 & \multirow[t]{6}{*}{$F(5,1183)=3.268$} & \multirow[t]{6}{*}{0.006} \\
\hline $21-25$ & 388 & 4.52 & 1.49 & & \\
\hline $26-30$ & 302 & 4.30 & 1.48 & & \\
\hline $31-35$ & 132 & 4.28 & 1.50 & & \\
\hline $36-40$ & 74 & 4.17 & 1.51 & & \\
\hline$>40$ & 79 & 3.94 & 1.50 & & \\
\hline \multicolumn{6}{|c|}{ Achievement } \\
\hline$<20$ & 215 & 4.96 & 1.19 & \multirow[t]{6}{*}{$F(5,1183)=5.062$} & \multirow[t]{6}{*}{$<0.001$} \\
\hline $21-25$ & 388 & 4.78 & 1.18 & & \\
\hline $26-30$ & 302 & 4.80 & 1.18 & & \\
\hline $31-35$ & 132 & 4.60 & 1.18 & & \\
\hline $36-40$ & 74 & 4.43 & 1.19 & & \\
\hline$>40$ & 79 & 4.33 & 1.18 & & \\
\hline \multicolumn{6}{|l|}{ Immersion } \\
\hline$<20$ & 215 & 5.10 & 1.26 & \multirow[t]{6}{*}{$F(5,1183)=3.685$} & \multirow[t]{6}{*}{0.003} \\
\hline $21-25$ & 388 & 5.03 & 1.26 & & \\
\hline $26-30$ & 302 & 4.95 & 1.27 & & \\
\hline $31-35$ & 132 & 4.69 & 1.26 & & \\
\hline $36-40$ & 74 & 5.01 & 1.26 & & \\
\hline$>40$ & 79 & 4.56 & 1.26 & & \\
\hline \multicolumn{6}{|c|}{ Physical exploration } \\
\hline$<20$ & 215 & 5.26 & 1.46 & \multirow[t]{6}{*}{$F(5,1183)=1.234$} & \multirow[t]{6}{*}{0.291} \\
\hline $21-25$ & 388 & 5.53 & 1.45 & & \\
\hline $26-30$ & 302 & 5.42 & 1.46 & & \\
\hline $31-35$ & 132 & 5.51 & 1.46 & & \\
\hline $36-40$ & 74 & 5.57 & 1.46 & & \\
\hline$>40$ & 79 & 5.31 & 1.47 & & \\
\hline \multicolumn{6}{|l|}{ Enjoyment } \\
\hline$<20$ & 215 & 5.30 & 1.40 & \multirow[t]{6}{*}{$F(5,1183)=1.756$} & \multirow[t]{6}{*}{0.119} \\
\hline $21-25$ & 388 & 5.54 & 1.42 & & \\
\hline $26-30$ & 302 & 5.26 & 1.41 & & \\
\hline $31-35$ & 132 & 5.46 & 1.41 & & \\
\hline $36-40$ & 74 & 5.56 & 1.41 & & \\
\hline$>40$ & 79 & 5.48 & 1.40 & & \\
\hline \multicolumn{6}{|l|}{ Coolness } \\
\hline$<20$ & 215 & 3.14 & 1.70 & \multirow[t]{6}{*}{$F(5,1183)=2.984$} & \multirow[t]{6}{*}{0.011} \\
\hline $21-25$ & 388 & 3.10 & 1.69 & & \\
\hline $26-30$ & 302 & 2.82 & 1.70 & & \\
\hline $31-35$ & 132 & 2.71 & 1.70 & & \\
\hline $36-40$ & 74 & 2.57 & 1.70 & & \\
\hline$>40$ & 79 & 2.74 & 1.69 & & \\
\hline \multicolumn{6}{|c|}{ Privacy concerns } \\
\hline$<20$ & 215 & 3.62 & 1.79 & \multirow[t]{6}{*}{$F(5,1183)=2.457$} & 0.032 \\
\hline $21-25$ & 388 & 3.73 & 1.79 & & \\
\hline $26-30$ & 302 & 4.05 & 1.79 & & \\
\hline $31-35$ & 132 & 4.12 & 1.78 & & \\
\hline $36-40$ & 74 & 3.94 & 1.78 & & \\
\hline$>40$ & 79 & 3.77 & 1.78 & & \\
\hline Nostalgia* & & & & & \\
\hline$<20$ & 215 & 3.90 & 1.42 & $F(5,1183)=64.626$ & $<0.001$ \\
\hline
\end{tabular}


Table 5 (continued)

\begin{tabular}{lccccc}
\hline Age group & $N$ & Mean & SD & ANCOVA & $p$ \\
\hline $21-25$ & 388 & 4.04 & 1.41 & \\
$26-30$ & 302 & 3.73 & 1.43 & \\
$31-35$ & 132 & 2.62 & 1.42 & \\
$36-40$ & 74 & 2.05 & 1.43 & \\
$>40$ & 79 & 1.78 & 1.42 & \\
\hline
\end{tabular}

Table 6 Inter-item correlation for survey instruments

\begin{tabular}{lcllllllll}
\hline & 1 & 2 & 3 & 4 & 5 & 6 & 7 & 8 & 9 \\
\hline Age & 1 & & & & & & & \\
Social & $-0.105^{* *}$ & 1 & & & & & & \\
Achievement & $-0.128^{* *}$ & $0.481^{* *}$ & 1 & & & & & \\
Immersion & $-0.094^{* *}$ & $0.623^{* *}$ & $0.592^{* *}$ & 1 & & & & \\
Physical & 0.020 & $0.631^{* *}$ & $0.395^{* *}$ & $0.626^{* *}$ & 1 & & & \\
Enjoyment & 0.020 & $0.575^{* *}$ & $0.411^{* *}$ & $0.720^{* *}$ & $0.661^{* *}$ & 1 & & \\
Coolness & $-0.093^{* *}$ & $0.539^{* *}$ & $0.450^{* *}$ & $0.430^{* *}$ & $0.314^{* *}$ & $0.337^{* *}$ & 1 & & \\
Privacy & $0.059^{*}$ & $0.201^{* *}$ & $0.184^{* *}$ & $0.205^{* *}$ & $0.192^{* *}$ & $0.219^{* *}$ & $0.175^{* *}$ & 1 & \\
Nostalgia & $-0.413^{* *}$ & $0.200^{* *}$ & $0.198^{* *}$ & $0.169^{* *}$ & 0.033 & $0.102^{* *}$ & $0.141^{* *}$ & -0.015 & 1 \\
\hline
\end{tabular}

*Correlation is significant at 0.05 level; **Correlation is significant at 0.01 level

contrary to the popular belief that, in general, males enjoy gaming more than females [20, 25, 63]. There can be multiple reasons behind this finding, e.g., type of game, game features, as well as the gamer population. The sample in our study is quite broad as compared to most of the prior gaming studies that focus predominantly on young male gamers $[9,11,21,37,50,58]$. The current study has a fairly wellbalanced sample representing a number of age groups as well as good representation of gender groups. Furthermore, an overwhelming majority of the study sample had fewer than five games installed on their smartphones (62.7\%), indicating that the sample size predominantly consists of highly casual gamers. Similarly, almost half of the study participants played games somewhere between $30 \mathrm{~min}$ and $2 \mathrm{~h}$ every day.

Considering the background of Pokémon Go, i.e., the causal nature of the game coupled with novel concepts, and most prominently, enjoyment supported in gaining more attraction among female players than males. It is also quite probable that the enjoyment motive (as well as other gratifications) is associated strongly with the game type and genre. For instance, many games studies have repeatedly indicated that males enjoy the violent features of the games far more than females [25, 57]. As Pokémon Go is a mobile casual game that attracts a large gamer demographic, it is highly likely that prior findings might not be valid for this game.

Female players also scored higher on physical exploration gratification associated with playing Pokémon Go. This is one of the other novel findings of this study, as we are unaware of any other study in the context of gaming that has explored this gratification. With respect to female players, it is highly likely that physical exploration highly correlates with and induces enjoyment gratification. Due to a highly novel gaming feature that encourages them to visit/explore new places as well as aids in improving their health and fitness, women seem to be enjoying the game much more than their male counterparts. The likelihood of being attracted by the physical exploration features of a game can be a response to the fact that women are generally more cautious and concerned about their health, and that leads them to use various technologies for seeking health-related information and support more actively than men [6]. Furthermore, they experience a higher degree of enjoyment while seeking health-related information through technology [6], which can be a possible explanation of this strong linkage.

Results also point out that males are more attracted by the nostalgia associated with the Pokémon Go game and characters. The core reason lies in the fact that in the timeframe of Gameboy, Pokécards, and the Pokémon series (late 1990s and early 2000s), gaming was predominantly a male activity as games were played mostly by teenage/young men. During that specific era, very few women were into gaming or watching anime/TV series, which was primarily malecentric [66]. Also, the social aspects of the Pokémon Go gaming experience, previously considered more important for females, seem to be more important to males. These findings suggest that the socializing aspects that are inherent among new types of gaming experiences appeal more to male users. In line with prior gaming studies [27, 31, 70], 
the results affirm that male players scored higher for achievement and coolness gratifications in Pokémon Go.

Another unexpected, yet intriguing finding from this study relates to the concerns associated with privacy. Most of the IS literature consistently points out that females are more concerned about various aspects of privacy, especially in the social networking domain [45, 46-48]. Our results, on the contrary, indicate that males are more concerned about privacy than females. The most obvious reason might be that female gamers never imagined that another person or organization can pose a threat to them or their gaming data through game play. It is quite likely that many female gamers have never heard of or experienced firsthand privacy breaches on their mobile devices due to a game. They might also believe that the game is developed and published by a well-known and reputable company (many players consider Nintendo as the publisher of Pokémon Go), hence their data is safe. As males generally play more games and are active on a number of gaming forums and communities, it is highly probable that they might have read, heard, or experienced privacy breaches associated with digital games.

With respect to age, the results from the current study also reiterate some of the commonly reported findings by prior gaming studies as well as reveal novel ones. Consistent with prior research, most of the common gaming gratifications including social, achievement, immersion, and coolness depict inverse linear patterns with age. Younger players of Pokémon Go are overwhelmingly attracted by these gratifications. With an increase in age, there is a consistent drop in the appeal of these gratifications. Physical explorations and enjoyment gratification do not significantly differ among the age groups, yet interestingly, the means of both are the highest among all the gratifications. Another highly interesting finding relates to the nostalgia factor among different age groups. This factor has been a significant one and stands out the most for the young adult age group. The Pokémon franchise, introduced in 1995, evolved over time and then reached the pinnacle of its popularity during the early 2000s, branching out through a number of anime series, TV specials, musicals and trading cards among other iterations. The association with the brand, characters, and the game itself seem to have revived and become more popular with the age groups that have interacted with the characters or brand when they were younger. Finally, with respect to concerns about privacy, it is lowest among the youngest and the oldest age groups. Results indicate that privacy concerns increase with age and the young/young-adult groups (26-30 and 31-35 years) are concerned the most with respect to privacy. These results are strongly in line with previous notions that teenagers and older age groups are largely less concerned about their privacy as the older users are generally unaware, while the younger ones seem not to take it seriously or have an "it won't happen to me" attitude [46-48, 61].

Overall findings from the current study highlight the complex nature of motivations when considering gender and age differences. The results highlight the fact that game design, demographics, motivations, and actual usage have changed over time alongside the emergence of new technologies. Two of the most important aspects of online games are the gaming experience and communication aspects. Socializing, exploration, physical activations, and enjoyment motivations seem to be popular among the participants in this study. These findings support the U\&G framework that suggests that people use technology in order to satisfy a wide range of needs. Online games are extrinsically rewarding as they deliver immediate access to other individuals and mobile applications. Moreover, they offer users the opportunity to customize, manipulate, and explore the virtual environment and their surroundings. Hence, in line with the U\&G framework, the features of augmented reality games, such as Pokémon Go, provide high-frequency rewards that promote regular usage and help satisfy the relevant needs of gamers hailing from multiple cohorts.

\subsection{Implications for game design and social computing}

In terms of implications for social computing research and game design, the results provide insights into social behavior and human social dynamics. Through their participatory nature, augmented reality games have opened a new dimension allowing users across different age cohorts, and in particular, females, to feel more empowered. This is an area for future research, which may include expanding the theoretical base for game design by drawing from more disciplines and guiding new business ventures. There is a strong need for cross-disciplinary research to bridge social and technical aspects associated with digital gaming. More generally, the present research study has implications for education, social sciences, and society at large. The results of the study add to the literature on augmented reality games by focusing on player motivations in a highly popular gaming phenomenon (i.e., Pokémon Go).

The study findings will be of interest to game developers and designers, as they signify how certain constructs play a role in playing online games. The findings also highlight the influence of structural characteristics in inducing play. The present study has shown that there are various motivations for playing online games and substantial differences prevail among gender and age groups. Designing gaming 
applications for niches as well as for broader demographics can provide insights on relevant motives and concerns. With the contemporary gaming arena leaning further toward mobile (and online) gaming, motivations such as physical exploration, social interaction, and nostalgia should be prioritized while crafting new games.

Digital games that make use of new technology (such as augmented reality) need to strongly emphasize and rely on some of the well-known features of human-computer interaction, which is socializing, physical pursuit, and competing against others. Game designers may consider these features to help improve augmented reality interactions, features, as well as overall gaming experiences. Interestingly, digital distribution platforms, rankings or positive online reviews, often mentioned as key success factors for mobile games, were among the least mentioned reasons for playing Pokémon Go, which infers that, at least for a game with strong prior brand recognition, these might not be as critical. As nostalgic association and word of mouth were regarded as highly significant reasons, future games can also target for these to promote their content. These suggestions provide designers and developers with the blueprint for successful augmented reality games in the future. More specifically, the present study suggests that the focus should be on the positive aspects of social computing.

\subsection{Study limitations}

The present study has several limitations, namely that the sample was self-selected and might not be a representative sample of online game users. In this sense, online game users who may be concerned about their playing behavior could have been attracted to the study in order to provide insights into their own game play. Secondly, few methodological issues surrounding the use of a self-report measure (e.g., social desirability bias, recall biases) are also present in the present study that could have been prevented by using other data sources such as those obtained with qualitative methods or with a case study approach. However, using alternative data collection methods in such a study may have resulted in a limited geographical reach, high dropout rate and considerably smaller sample size being obtained. Even though majority of the respondents can be categorized as casual gamers as $62.7 \%$ of them have less than 5 games installed on their phones, it is probable that the current sampling method might be potentially biased. It is somewhat likely that the respondents may be the "hard core Pokémon gamers" who follow game-related social media, blogs, or gaming forums, and the results might or might not be generalizable to "casual gamers" who do not follow such channels. Even if this holds true, understanding the motivations of this specific audience (hard core gamers) is also highly relevant and interesting for practitioners and researchers, since they are the ones who are more likely to invest money and spend more time in online gaming.

\section{Conclusion}

With the increasing use of online and mobile games worldwide, investigating the motivations for playing different games on various platforms offers highly relevant and essential insights to researchers, developers, designers as well as policymakers. We present findings from a study that examines the effects of age, gender, uses, and motives in the relatively new phenomenon of locationbased augmented reality games. The study has set the way for a deeper analysis of motivation factors and associated concerns among different cohorts of players. Understanding motivations for play can provide researchers with the analytic tools to gain insight into the preferences for and effects of game play for different kinds of users. Future research could make use of data mining techniques to test real-time data gathered by users to gain a deeper insight into online game use. Also using more innovative techniques that allow researchers to gather location-specific data (via location tracker apps) would allow for comparisons across countries and cultures. This would provide further insights into how users of new technology interact with augmented reality games.

Acknowledgements Open access funding provided by Aalto University. This work is supported in part by US National Science Foundation Awards \#142444 and \#1707837 (PI: Johri), Business Finland (40009/16, 5654/31/2018), and Satakunnan Korkeakoulusäätiö. Any opinions, findings, and conclusions or recommendations expressed in this material are those of the authors and do not necessarily reflect the views of the funding agencies.

\section{Compliance with ethical standards}

Conflict of interest On behalf of all authors, the corresponding author states that there is no conflict of interest.

Open Access This article is distributed under the terms of the Creative Commons Attribution 4.0 International License (http://creativeco mmons.org/licenses/by/4.0/), which permits unrestricted use, distribution, and reproduction in any medium, provided you give appropriate credit to the original author(s) and the source, provide a link to the Creative Commons license, and indicate if changes were made.

\section{Appendix}

See Table 7. 
Table 7 Survey constructs, description, items, and sources

\begin{tabular}{|c|c|c|c|}
\hline Construct & Description & Items & Source(s) \\
\hline $\begin{array}{l}\text { Achievement } \\
1=\text { strongly disagree, } \\
7=\text { strongly agree }\end{array}$ & $\begin{array}{l}\text { The desire to gain power, compete, } \\
\text { progress and accumulate in-game } \\
\text { status }\end{array}$ & $\begin{array}{l}\text { ACH_1: Feel proud when I master an aspect of } \\
\text { the game } \\
\text { ACH_2: Feels rewarding to get to the next level } \\
\text { ACH_3: Feel excited when I catch a new } \\
\text { Pokémon } \\
\text { ACH_4: Feel excited when I win a battle } \\
\text { ACH_5: Like to prove that I am one of the best } \\
\text { player } \\
\text { ACH_6: Get upset when other do better than me } \\
\text { ACH_7:, Get upset when I am unable to earn } \\
\text { enough points } \\
\text { ACH_8: Important to be one of the skilled } \\
\text { person playing the game }\end{array}$ & $\begin{array}{l}\text { Yee [70], Hassouneh and } \\
\text { Brengman [27] }\end{array}$ \\
\hline $\begin{array}{l}\text { Social interaction } \\
1=\text { strongly disagree, } \\
7=\text { strongly agree }\end{array}$ & $\begin{array}{l}\text { Deriving pleasure from belonging } \\
\text { and participating in interactions } \\
\text { with other people or groups }\end{array}$ & $\begin{array}{l}\text { SOC_1: Playing Pokémon Go to maintain } \\
\text { friendship } \\
\text { SOC_2: Playing Pokémon Go to improve } \\
\text { relationships } \\
\text { SOC_3: Playing Pokémon Go to make new } \\
\text { friends } \\
\text { SOC_4: Playing Pokémon Go because friends } \\
\text { play the game } \\
\text { SOC_5: Playing Pokémon Go to participate in } \\
\text { relevant discussions } \\
\text { SOC_6: Playing Pokémon Go is be part of a } \\
\text { group } \\
\text { SOC_7: Playing Pokémon Go to meet friends }\end{array}$ & $\begin{array}{l}\text { Yee [70], Wei and Lu [64], } \\
\text { Sherry et al. [58] }\end{array}$ \\
\hline $\begin{array}{l}\text { Immersion } \\
1=\text { strongly disagree, } \\
7=\text { strongly agree }\end{array}$ & $\begin{array}{l}\text { The extent of being involved in a } \\
\text { game }\end{array}$ & $\begin{array}{l}\text { IMM_1: Playing Pokémon Go is a good pastime } \\
\text { IMM_2: Playing Pokémon Go is a habit } \\
\text { IMM_3: Playing Pokémon Go occupies my free } \\
\text { time } \\
\text { IMM_4: Enjoy finding new and creative ways to } \\
\text { work through the game }\end{array}$ & Yee [70] \\
\hline $\begin{array}{l}\text { Physical Exploration } \\
1=\text { strongly disagree, } \\
7=\text { strongly agree }\end{array}$ & $\begin{array}{l}\text { The gratifications associated with } \\
\text { exploring physical world }\end{array}$ & $\begin{array}{l}\text { PHY_1: Playing Pokémon Go to go out } \\
\text { PHY_2: Playing Pokémon Go to explore new } \\
\text { places } \\
\text { PHY_3: Playing Pokémon Go physically } \\
\text { activates } \\
\text { PHY_4: Playing Pokémon Go improve health }\end{array}$ & Self-developed \\
\hline $\begin{array}{l}\text { Enjoyment } \\
1=\text { strongly disagree, } \\
7=\text { strongly agree }\end{array}$ & $\begin{array}{l}\text { Hedonistic fun and enjoyment gained } \\
\text { from playing the game }\end{array}$ & $\begin{array}{l}\text { ENJ_1: Playing Pokémon Go is exciting } \\
\text { ENJ_2: Playing Pokémon Go is entertaining } \\
\text { ENJ_3: Playing Pokémon Go is fun }\end{array}$ & $\begin{array}{l}\text { Wei and Lu [64], Kim and } \\
\text { Ross [37] }\end{array}$ \\
\hline $\begin{array}{l}\text { Coolness } \\
1=\text { strongly disagree, } \\
7=\text { strongly agree }\end{array}$ & $\begin{array}{l}\text { Hedonistic desire to be cool, fashion- } \\
\text { able and timely }\end{array}$ & $\begin{array}{l}\text { COO_1: Playing Pokémon Go to look trendy } \\
\text { COO_2: Playing Pokémon Go look cool } \\
\text { COO_3: Playing Pokémon Go to look stylish }\end{array}$ & $\begin{array}{l}\text { Quan-Haase and Young [53], } \\
\text { Leung and Zhang [42] }\end{array}$ \\
\hline $\begin{array}{l}\text { Privacy concerns } \\
1=\text { strongly disagree, } \\
7=\text { strongly agree }\end{array}$ & $\begin{array}{l}\text { Worries of an individual with respect } \\
\text { to access of her personal data by } \\
\text { others }\end{array}$ & $\begin{array}{l}\text { CON_1: Concerned that data being transferred } \\
\text { to Niantic } \\
\text { CON_2: Concerned that data being used by } \\
\text { Niantic } \\
\text { CON_3: Concerned that data being shared with } \\
\text { third parties }\end{array}$ & $\begin{array}{l}\text { Taddicken [61], Malik et al. } \\
\text { [46-48] }\end{array}$ \\
\hline $\begin{array}{l}\text { Nostalgia } \\
\text { (yes(1)/no (0) questions } \\
\text { summed into a single } \\
\text { variable) }\end{array}$ & $\begin{array}{l}\text { A state of sentimental longing* of } \\
\text { the past (*positive ones in the cur- } \\
\text { rent study perspective) }\end{array}$ & $\begin{array}{l}\text { NOS_1: Used to play games on "Nintendo } \\
\text { Game boy" } \\
\text { NOS_2: Used to play Pokémon PC/Console } \\
\text { games } \\
\text { NOS_3: Used to watch Pokémon cartoons/ } \\
\text { anime series/movies } \\
\text { NOS_4: Used to collect Pokémon merchandise } \\
\text { NOS_5: Fan of Pokémon even before the launch } \\
\text { of Pokémon GO }\end{array}$ & Self-developed \\
\hline
\end{tabular}




\section{References}

1. Alha, K., Koskinen, E., Paavilainen, J., Hamari, J.: Why do people play location-based augmented reality games: a study on Pokémon GO. Comput. Hum. Behav. 93, 114-122 (2019)

2. Althoff, T., White, R.W., Horvitz, E.: Influence of Pokémon Go on physical activity: study and implications. J. Med. Internet Res. 18(12), e315 (2016)

3. Ayers, J.W., Leas, E.C., Dredze, M., et al.: Pokémon GO-a new distraction for drivers and pedestrians. JAMA Intern. Med. 176(12), 1865-1866 (2016)

4. Battista, R.A., West, S.T., Mackenzie, S.H., et al.: Is this exercise? No, it's geocaching! Exploring factors related to aspects of geocaching participation. J. Park Recreat. Adm. 34(2), 30-48 (2016)

5. Benfield, J.A., Szlemko, W.J.: Internet-based data collection: promises and realities. J. Res. Pract. 2(2), 1 (2006)

6. Bidmon, S., Terlutter, R.: Gender differences in searching for health information on the internet and the virtual patient-physician relationship in Germany: exploratory results on how men and women differ and why. J. Med. Internet Res. 17(6), e156 (2015)

7. Błachnio, A., Przepiórka, A., Pantic, I.: Internet use, Facebook intrusion, and depression: results of a cross-sectional study. Eur. Psychiatry 30(6), 681-684 (2015)

8. Bonus, J.A., Peebles, A., Mares, M.-L., et al.: Look on the bright side (of media effects): Pokémon Go as a catalyst for positive life experiences. Media Psychol. (2017). https://doi. org/10.1080/15213269.2017.1305280

9. Borgonovi, F.: Video gaming and gender differences in digital and printed reading performance among 15-year-olds students in 26 countries. J. Adolesc. 48, 45-61 (2016)

10. Caci, B., Scrima, F., Tabacchi, M.E., Cardaci, M.: The reciprocal influences among motivation, personality traits, and game habits for playing Pokémon GO. Int. J. Hum. Comput. Interact. 35(14), 1303-1311 (2019)

11. Calado, F., Alexandre, J., Griffiths, M.D.: Mom, Dad it's only a game! perceived gambling and gaming behaviors among adolescents and young adults: an exploratory study. Int. J. Mental Health Addict. 12(6), 772-794 (2014)

12. Chen, C., Leung, L.: Are you addicted to Candy Crush Saga? An exploratory study linking psychological factors to mobile social game addiction. Telemat. Inform. 33(4), 1155-1166 (2016)

13. Chess, S.: Augmented regionalism: ingress as geomediated gaming narrative. Inf. Commun. Soc. 17(9), 1105-1117 (2014)

14. Colley, A., Thebault-Spieker, J., Lin, A.Y., et al.: The geography of Pokémon GO: beneficial and problematic effects on places and movement. In: Proceedings of the SIGCHI Conference on Human Factors in Computing Systems (2017)

15. Cota, T.T., Ishitani, L., Vieira, N.: Mobile game design for the elderly: a study with focus on the motivation to play. Comput. Hum. Behav. 51, 96-105 (2015)

16. Crowston, K., Kammerer, E.: Communicative style and gender differences in computer-mediated communications. In: Ebo, B. (ed.) Cyberghetto or cybertopia? Race, class, and gender on the Internet, pp. 185-203. Praeger, Westport, Conn (1998)

17. Dabbish, L., Kraut, R., Patton, J.: Communication and commitment in an online game team. In: Proceedings of the SIGCHI Conference on Human Factors in Computing Systems, 2012, pp. 879-888. ACM (2012)

18. Forgays, D.K., Hyman, I., Schreiber, J.: Texting everywhere for everything: gender and age differences in cell phone etiquette and use. Comput. Hum. Behav. 31, 314-321 (2014)

19. Ghazali, E., Mutum, D.S., Woon, M.-Y.: Exploring player behavior and motivations to continue playing Pokémon GO. Inf. Technol. People 32(3), 646-667 (2018)
20. Greenberg, B.S., Sherry, J., Lachlan, K., et al.: Orientations to video games among gender and age groups. Simulation \& Gaming 41(2), 238-259 (2010)

21. Griffiths, M.D., Davies, M.N., Chappell, D.: Online computer gaming: a comparison of adolescent and adult gamers. J. Adolesc. 27(1), 87-96 (2004)

22. Haimson, O.L., Andalibi, N., De Choudhury, M., et al.: Relationship breakup disclosures and media ideologies on Facebook. New Media Soc. 20, 1931-1952 (2017)

23. Hamari, J., Malik, A., Koski, J., Johri, A.: Uses and gratifications of Pokémon Go: why do people play mobile location-based augmented reality games? Int. J. Hum. Comput. Interact. 35(9), 804-819 (2019)

24. Hamari, J., Keronen, L.: Why do people play games? A metaanalysis. Int. J. Inf. Manag. 37(3), 125-141 (2017)

25. Hartmann, T., Klimmt, C.: Gender and computer games: exploring females' dislikes. J. Comput. Mediat. Commun. 11(4), 910-931 (2006)

26. Hasan, B.: Exploring gender differences in online shopping attitude. Comput. Hum. Behav. 26(4), 597-601 (2010)

27. Hassouneh, D., Brengman, M.: A motivation-based typology of social virtual world users. Comput. Hum. Behav. 33, 330-338 (2014)

28. Hou, J.: Uses and gratifications of social games: blending social networking and game play. First Monday 16(7) (2011)

29. Hsu, C.-L., Lu, H.-P.: Why do people play on-line games? An extended TAM with social influences and flow experience. Inf. Manag. 41(7), 853-868 (2004)

30. Hulsey, N., Reeves, J.: The gift that keeps on giving: Google, Ingress, and the gift of surveillance. Surveill. Soc. 12(3), 389 (2014)

31. Hussain, Z., Griffiths, M.D.: Gender swapping and socializing in cyberspace: an exploratory study. CyberPsychol. Behav. 11(1), 47-53 (2008)

32. Hussain, Z., Griffiths, M.D.: The attitudes, feelings, and experiences of online gamers: a qualitative analysis. CyberPsychol. Behav. 12(6), 747-753 (2009)

33. Hussain, Z., Griffiths, M.D.: A qualitative analysis of online gaming. Int. J. Cyber Behav. Psychol. Learn. 4(2), 41-57 (2014)

34. Hussain, Z., Williams, G.A., Griffiths, M.D.: An exploratory study of the association between online gaming addiction and enjoyment motivations for playing massively multiplayer online role-playing games. Comput. Hum. Behav. 50, 221-230 (2015)

35. Jansz, J., Tanis, M.: Appeal of playing online first person shooter games. CyberPsychol. Behav. 10(1), 133-136 (2007)

36. Kaye, B.K., Johnson, T.J.: Online and in the know: uses and gratifications of the web for political information. J. Broadcast. Electron. Media 46(1), 54-71 (2002)

37. Kim, Y., Ross, S.D.: An exploration of motives in sport video gaming. Int. J. Sports Mark. Spons. 8(1), 28-40 (2006)

38. Koivisto, J., Malik, A., Gurkan, B., Hamari, J.: Getting healthy by catching them all: a study on the relationship between player orientations and perceived health benefits in an augmented reality game. In Proceedings of the 52nd Hawaii International Conference on System Sciences (2019)

39. Koivisto, J., Hamari, J.: Demographic differences in perceived benefits from gamification. Comput. Hum. Behav. 35, 179-188 (2014)

40. Kogan, L., Hellyer, P., Duncan, C., et al.: A pilot investigation of the physical and psychological benefits of playing Pokémon GO for dog owners. Comput. Hum. Behav. 76(Supplement C), 431-437 (2017). https://doi.org/10.1016/j.chb.2017.07.043

41. Lampe, C., Wash, R., Velasquez, A., et al.: Motivations to participate in online communities. In: Proceedings of the SIGCHI Conference on Human Factors in Computing Systems, 2010, pp. 1927-1936. ACM (2010) 
42. Leung, L., Zhang, R.: Predicting tablet use: A study of gratifications-sought, leisure boredom, and multitasking. Telematics. Inform. 33(2), 331-341 (2016)

43. Lucas, K., Sherry, J.L.: Sex differences in video game play: a communication-based explanation. Commun. Res. 31(5), 499-523 (2004)

44. Magsamen-Conrad, K., Dowd, J., Abuljadail, M., et al.: Life-span differences in the uses and gratifications of tablets: implications for older adults. Comput. Hum. Behav. 52, 96-106 (2015)

45. Malik, A., Dhir, A., Nieminen, M.: Facebook photo tagging culture and practices among digital natives. In CCGIDIS 2015-Fifth International Symposium on Communicability, Computer Graphics and Innovative Design for Interactive Systems (2015)

46. Malik, A., Dhir, A., Nieminen, M.: Uses and gratifications of digital photo sharing on Facebook. Telemat. Inform. 33(1), 129-138 (2016)

47. Malik, A., Hiekkanen, K., Nieminen, M.: Privacy and trust in Facebook photo sharing: age and gender differences. Program 50(4), 462-480 (2016)

48. Malik, A., Hiekkanen, K., Dhir, A., Nieminen, M.: Impact of privacy, trust and user activity on intentions to share Facebook photos. J. Inf. Commun. Ethics Soc. 14(4), 364-382 (2016)

49. McCartney, M.: Game on for Pokémon Go. BMJ 354, i4306i4306 (2016)

50. Merhi, M.I.: Towards a framework for online game adoption. Comput. Hum. Behav. 60, 253-263 (2016)

51. Nouchi, R., Taki, Y., Takeuchi, H., et al.: Brain training game improves executive functions and processing speed in the elderly: a randomized controlled trial. PLoS ONE 7(1), e29676 (2012)

52. O'Hara, K.: Understanding geocaching practices and motivations. In: Proceedings of the SIGCHI Conference on Human Factors in Computing Systems, 2008, pp. 1177-1186. ACM (2008)

53. Quan-Haase, A., Young, A.L.: Uses and gratifications of social media: a comparison of Facebook and instant messaging. Bull. Sci. Technol. Soc. 30(5), 350-361 (2010)

54. Rauschnabel, P.A., Rossmann, A., tom Dieck, M.C.: An adoption framework for mobile augmented reality games: the case of Pokémon Go. Comput. Hum. Behav. 76, 276-286 (2017)

55. Rubin, A.M.: Uses and gratifications. In: The SAGE Handbook of Media Processes and Effects, pp 147-159. SAGE, Los Angeles (2009)

56. Sharit, J., Taha, J., Berkowsky, R.W., et al.: Seeking and resolving complex online health information age differences in the role of cognitive abilities. In: Proceedings of the Human Factors and Ergonomics Society Annual Meeting, 2016, pp. 1-5. SAGE Publications (2016)

57. Shen, C., Ratan, R., Cai, Y.D., et al.: Do men advance faster than women? Debunking the gender performance gap in two massively multiplayer online games. J. Comput. Mediat. Commun. 21(4), 312-329 (2016)
58. Sherry, J.L., Lucas, K., Greenberg, B.S., et al.: Video game uses and gratifications as predictors of use and game preference. Play. Video Games Motiv. Responses Conseq. 24, 213-224 (2006)

59. Sobel, K., Bhattacharya, A., Hiniker, A., et al.: "It wasn't really about the Pokémon": parents' perspectives on a location-based mobile game (2017). http://students.washington.edu/alexisr/ PokemonGO.pdf. Accessed 8 Mar 2017

60. Straub, D., Boudreau, M.-C., Gefen, D.: Validation guidelines for IS positivist research. Commun. Assoc. Inf. Syst. 13(1), 63 (2004)

61. Taddicken, M.: The 'Privacy Paradox' in the social web: the impact of privacy concerns, individual characteristics, and the perceived social relevance on different forms of self-disclosure. J. Comput. Mediat. Commun. 19(2), 248-273 (2014)

62. Vaterlaus, J.M., Frantz, K., Robecker, T.: "Reliving my childhood dream of being a Pokémon Trainer": An exploratory study of college student uses and gratifications related to Pokémon Go. Int. J. Hum. Comput. Interact. 35(7), 596-604 (2018)

63. Wang, S.S., Hsu, S.-J.: Not so angry birds: psychological benefits of mobile games. Pac. Asia J. Assoc. Inf. Syst. 8(1), 65-84 (2016)

64. Wei, P.-S., Lu, H.-P.: Why do people play mobile social games? An examination of network externalities and of uses and gratifications. Internet Res. 24(3), 313-331 (2014)

65. Whitbourne, S.K., Ellenberg, S., Akimoto, K.: Reasons for playing casual video games and perceived benefits among adults 18 to 80 years old. Cyberpsychol. Behav. Soc. Netw. 16(12), 892-897 (2013)

66. Williams, D.: The video game lightning rod. Inf. Commun. Soc. 6(4), 523-550 (2003)

67. Williams, D., Martins, N., Consalvo, M., et al.: The virtual census: representations of gender, race and age in video games. New Media Soc. 11(5), 815-834 (2009)

68. Wu, J.-H., Wang, S.-C., Tsai, H.-H.: Falling in love with online games: the uses and gratifications perspective. Comput. Hum. Behav. 26(6), 1862-1871 (2010)

69. Yang, C., Liu, D.: Motives matter: motives for playing Pokémon Go and implications for well-being. Cyberpsychol. Behav. Soc. Netw. 20(1), 52-57 (2017)

70. Yee, N.: Motivations for play in online games. Cyberpsychol. Behav. 9(6), 772-775 (2006)

71. Yee, N.: Maps of digital desires: exploring the topography of gender and play in online games. In: Beyond Barbie and Mortal Kombat: New Perspectives on Gender and Gaming, pp. 83-96 (2008)

72. Zsila, Á., Orosz, G., Bothe, B., et al.: An empirical study on the motivations underlying augmented reality games: the case of Pokémon Go during and after Pokémon fever. Pers. Individ. Differ. 133, 56-66 (2017)

Publisher's Note Springer Nature remains neutral with regard to jurisdictional claims in published maps and institutional affiliations. 